\section{The first Royal College}

Sir: I had the opportunity to see a book by Julius (1844) about his two visits to British asylums in 1834 and 1841 . In both years he visited Hanwell and Conolly. The book tells us that it was written during the journey, but published later. Julius recounts the founding of an English association of psychiatrists and complains about the fact that in Germany such a society did not yet exist in spite of several attempts to found one. This, I think, makes it clear that what is now the Royal College in fact was the first in the world; the German association came second, founded in 1842.

The book is in itself interesting enough about early English-German relations in psychiatry. It contains also a German translation of the long foreword, which had been written by Samuel Tuke for the English translation of Maximilian Jacobl's (1834) book on the management of psychiatric institutions. The translation had been made at the instance of Tuke.

JACOBI, K. W. M. (1834) Ueber die Anlegung und Einrichtung von Irren-Hellanstalten mit ausführlicher Darstellung der Irren-Hellanstalt zu Siegburg. Berlin: G. Reimers. (English translation ed. by Samuel Tuke (1841) On the Construction and Management of Hospitals for the Insane.)

JuLuUs, N. H. (1841) Beiträge zur britischen Irrenhellkunde. aus eigenen Anschauungen im Jahre 1841. Berlin: Enslin.

\section{U. H. PETERS}

Klinik und Poliklinik für Neurologie und

Psychiatrie der Universität zu Köln, Germany

\section{Longitudinal screening of thyroid dysfunction in adults with Down's syndrome}

Sir: A clinical, pathological and immunological association between thyroid dysfunction (TD) and Down's syndrome (DS) is well established (Pueschel et al, 1991). TD is a heterogenous disorder, with definite hypothyroidism and subclinical hypothyroidism being the two commonest abnormalities. There is, however, an absence of information regarding longitudinal findings of TD in people with DS.

Of 201 adults with DS recently screened for TD (Prasher, 1994) thyroid status results were available for 52 subjects for three consecutive years. Six subjects were excluded as they were being treated with thyroxine replacement during the study period. Mean age for the remaining 46 subjects at the start was 44.85 years (s.d. $=13.68$; range 19-71 years). Twenty-eight (61\%) were male and $18(39 \%)$ female.

Findings confirmed the high prevalence of TD in adults with DS; $48.1 \%$ at initial testing. Most individuals who were euthyroid at the start remained so two years later (85\%). Four subjects developed abnormalities within the following two years (incidence rate per year 7.4\%). Eight (17\%) subjects had subclinical hypothyroidism on initial testing of which three (38\%) reverted back to being euthryoid two years later. Only one subject with subclinical hypothyroidism at the start of the study went on to develop definite hypothyroidism at the two-year follow-up. The incidence rate for subclinical subjects to develop definite hypothyroidism was $6 \%$ per year. Fluctuations in mean free T4 and thyroid stimulating hormone (TSH) levels for the group as a whole occurred over the two-year study period (Friedman twoway ANOVA=8.4 and 10.1 respectively; $P=0.01$ ).

Thyroid dysfunction in adults with DS is a heterogenous disorder consisting of transient and persistent abnormalities. A significant number of adults with normal thyroid status will develop TD during the following two years (incidence rate of $15 \%$ ) but few will develop definite hypothyroidism. Further, plasma levels of free T4 and TSH can fluctuate significantly over a short period. Longitudinal data is important to understand the natural history of TD in people with DS. It will enable doctors to determine how often testing of thyroid status should be undertaken in individuals for whom venesection can be difficult, and to determine whether borderline and/or transient changes require treatment. Further areas of research investigating prognostic value of antibody determinations along with cost-benefit aspects of thyroid screening are recommended.

PRASher, V. P. (1994) Prevalence of thyroid dysfunction and autoimmunity in adults with Down's syndrome. Down's Syndrome Research and Practice, 2, 67-70.

Pueschel, S. M. \& PezzuLlo, J. C. (1985) Thyrold dysfunction in Down's syndrome. American Journal of Diseases of Children. 139. 636-639.

-. Jackson, I., Gresswern, P., et al (1991) Thyroid dysfunction in Down's syndrome. Research in Developmental Disabilities, 12, 287-296.

\section{PRASHER}

Lecturer in Psychiatry, Department of Psychiatry. University of Birmingham, Birmingham B15 2QZ

\section{The time span of the mental state examination}

Sir: The mental state examination (MSE) is the most important and often the only objective part of the psychiatric assessment. The MSE is the equivalent of the physical examination in the rest of medicine and is considered to be a cross sectional examination. There seems to be disagreement among experts as to the time span covered in the MSE. For some, it describes what is happening at that moment. For example, while assessing mood, they stick to the subjective and 